\title{
Motivos e Consequências da Falência de Agroindústrias Canavieiras no Estado do Paraná
}

\author{
Claudelir Clein $^{1}$ (D) | Pery Francisco Assis Shikida ${ }^{2}$ (D) | Luciano Rodrigues ${ }^{3}$ \\ ${ }^{1}$ Doutor em Desenvolvimento Regional e Agronegócio. Universidade Estadual do Oeste do Paraná. Universidade \\ Tecnológica Federal do Paraná. E-mail: claudeliradm@gmail.com \\ 2 Doutor em Economia Aplicada. Professor da Universidade Estadual do Oeste do Paraná. E-mail: \\ peryshikida@hotmail.com \\ ${ }^{3}$ Doutor em Economia Aplicada. Programa de Mestrado em Agronegócio na Fundação Getúlio Vargas (FGV/EESP). \\ E-mail: lurodrig@usp.br
}

\begin{abstract}
RESUMO
Este estudo procurou evidenciar e analisar quais os motivos e consequências da falência de agroindústrias canavieiras no Paraná, mediante duas abordagens (quantitativa e qualitativa). Neste sentido, o modelo de dados em painel dinâmico buscou verificar por meio da utilização de dados secundários para o período 2007 a 2016, como se comportou o PIB de 5 cidades paranaenses (Cambará, Engenheiro Beltrão, Perobal, Porecatu e Rolândia), onde existiam agroindústrias canavieiras que atuavam como forças motrizes e faliram. As contribuições da análise quantitativa sugerem que o PIB dos 5 municípios estudados, de certa forma, apresentou relação com a quebra das usinas. Os resultados do método qualitativo, o qual teve como instrumento de levantamento de informações a aplicação de questionário através de pesquisa de campo, segundo apontaram os dez representantes dos setores públicos e privados, todos com forte conhecimento de causa no setor sucroenergético (de forma geral), deu-se na redução de empregos, renda e arrecadação. Quanto aos fatores considerados determinantes para o fechamento das unidades pesquisadas, verificou-se que a falta de gestão foi o principal motivo para a falência das usinas.
\end{abstract}

\section{PALAVRAS-CHAVE}

Economia canavieira, Análise de mercado, Falência, Dados em painel, Pesquisa de campo, Paraná

\section{Reasons and Consequences of the Sugarcane Agribusinesses Bankruptcy in the State of Paraná}

\begin{abstract}
This study sought to highlight and analyze the reasons and consequences of the sugarcane agroindustries bankruptcy in the state of Paraná through quantitative and qualitative approaches. In this regard, the dynamic panel data model sought to verify, through the use of secondary data for the period 2007 to 2016, the GDP of 5 cities in Paraná (Cambará, Engenheiro Beltrão, Perobal, Porecatu, and Rolândia), where sugarcane agroindustries existed as driving forces and went bankrupt. The quantitative analysis contributions suggest that the GDP of the 5 municipalities studied was related to the collapse of the plants in a way. The results of the qualitative method, which had the application of a questionnaire through field research as a tool for gathering information, as pointed out by the ten representatives of the public and private sectors with solid knowledge on the sugar-energy sector (in general), showed the reduction of jobs, income, and collection. As for the factors considered decisive for the closure of the surveyed units, the lack of management was found as the main reason for the failure of the plants.
\end{abstract}

\section{KEYWORDS}

Sugarcane economy, Market analysis, Bankruptcy, Panel data, Field research, Paraná

\section{CLASSIFICAÇÃO JEL \\ Q12, Q13}




\section{Introdução}

Com um legado de mais de quatro séculos, a cultura canavieira no Brasil tem sido objeto de muitas análises acadêmicas. Pina (1972) ressalta que o cultivo da canade-açúcar faz parte da história agropecuária nacional como nenhuma outra cultura faz. Neves et al. (2011), em contexto analítico mais recente da economia (séculos XX e XXI), destacam que a agroindústria canavieira brasileira tem grande relevância por proporcionar - em alta escala - dois importantes produtos, o açúcar, para a segurança alimentar, e o etanol, para a segurança energética.

Dados da economia canavieira no Brasil apontam que foram produzidos, na safra 2019/2020, 642,7 milhões de toneladas de cana, que resultaram na produção de 29,6 milhões de toneladas de açúcar ( $2^{\circ}$ maior produtor mundial dessa commodity) e 35,6 milhões de litros de etanol total ( $2^{\circ}$ maior produtor mundial). Foram geradas divisas de US\$ 5,5 bilhões com as exportações açucareiras e US\$ 981,9 milhões com as exportações alcooleiras (UNICA-União da Indústria de Cana-de-Açúcar, 2021). Mesmo diante desses números, a produção canavieira no Brasil, desde a safra 2015/2016, decresceu, voltando a se recuperar apenas na safra 2019/2020.

Alguns problemas enfrentados por este setor geraram muita instabilidade ao longo da sua história. Esse é o caso do etanol na matriz energética no País que "[...] não foi delineada a partir de um plano objetivo e transparente, com mecanismos e medidas específicas a esse mercado", tanto que em determinados momentos seu ideário de segurança energética sustentável sucumbiu ante às preocupações com o avanço da inflação e/ou déficit público (Rodrigues, 2015, p. 106).

De forma geral, em todo o País as usinas e destilarias estão passando por uma reorganização de suas estruturas produtivas. Essas unidades produtivas procuram melhores formas de produção, inovação de produtos, processos e gestão organizacional, para fazer frente ao competitivo mercado sucroalcooleiro (Rissardi Júnior, 2015). Contudo, se algumas usinas e destilarias procuram sobreviver nesse cenário, outras estão quebrando. Goebel et al. (2020), em estudo que teve como intento apresentar um panorama da falência e recuperação judicial das agroindústrias canavieiras no Paraná, averiguaram que o motivo comum da crise nessas firmas decorre de dois tipos de problemas. O primeiro, de ordem microeconômica, relaciona-se com a gestão inadequada e adversidades climáticas; o segundo está associado com questões macroeconômicas, como redução de crédito e políticas erráticas de precificação dos combustiveis em alguns momentos. Dessa forma, o presente estudo difere de Goebel et al. (2020) por apresentar através de estudo de caso, além dos motivos, as consequências da falência das agroindústrias para os municípios pesquisados, tanto por meio de abordagem qualitativa como por meio de abordagem quantitativa.

Com politicas governamentais equivocadas para o setor (como o represamento dos preços dos derivados do petróleo), recrudesceu-se o desenvolvimento desigual entre essas organizações, principalmente para as que esperavam por iniciativas corretivas 
do governo. Outrossim, em uma atividade que estava acostumada com subvenções públicas, mas que com a desregulamentação teve que se adequar ao mercado, inconstâncias serão comuns (Siqueira et al., 2017).

Embora este setor, de modo geral, tenha vivenciado uma fase de crescimento de 2002 a 2007, a partir do ano de 2008 muitos desafios se estabeleceram por variados motivos, sendo um deles a crise internacional que impactou negativamente muitos países, inclusive o Brasil. Diante da situação financeira precária com a qual se deparavam algumas agroindústrias canavieiras, a crise internacional agravou ainda mais suas condições de sobrevivência. Como se não bastasse, no segundo governo Dilma, a prática de represamento dos preços dos combustiveis fósseis, com o fito de controlar a inflação, prejudicou ainda mais este segmento produtivo (Ferreira e Vieira Filho, 2019).

Bechlin et al. (2020, p. 252) corroboram que este setor vem passando por um momento difícil, porquanto: "no início de 2019, de um total de 444 usinas instaladas no País, 22,75\% estão paradas. Das 343 usinas que estão operando, 4 estão com status jurídico 'falida' e 48 em 'recuperação judicial'". Tal situação prejudica, com maior intensidade, os pequenos municípios onde essas unidades produtivas funcionam como força motriz, em que boa parte dos trabalhadores locais tem vínculo direto e/ou indireto com as usinas ou destilarias.

Isto posto, o objetivo deste trabalho consiste em analisar quais os motivos e as consequências da falência de agroindústrias canavieiras no Estado do Paraná. Para isto, utilizam-se os instrumentais quantitativo e qualitativo (intercalados entre si) como procedimento metodológico.

A partir de um instrumental quantitativo, procura-se estimar e analisar o que houve com municípios paranaenses (Cambará, Engenheiro Beltrão, Perobal, Porecatu e Rolândia) que tiveram agroindústrias canavieiras que faliram. Cumpre destacar que essas unidades produtivas atuavam como forças motrizes nessas localidades. Vale mencionar que uma indústria motriz, em uma determinada localidade de contingente populacional relativamente reduzido, ao crescer tem o poder de afetar a estrutura econômica e populacional por meio da expansão da renda regional. Ao revés, ao falir, o efeito é reverso. A periodização temporal escolhida compreende 2007 a 2016.

O estudo qualitativo procura, via pesquisa de campo, investigar e analisar a percepção dos agentes econômicos municipais ligados, direta e indiretamente, com agroindústrias selecionadas que malograram. Buscar informações primárias sobre os fatores relacionados à falência dessas empresas, bem como sua influência sobre os aspectos econômico e social para os municípios onde existiam, torna-se premente para entender não somente as causas desse quadro, como as suas consequências.

Isto posto, este estudo é composto por cinco seções, incluindo esta. A segunda seção destaca uma breve revisão de literatura. Na terceira seção são evidenciados os procedimentos metodológicos utilizados para as análises quantitativa e qualitativa. Os 
resultados e discussões compõem a quarta cinco. A seção cinco finaliza este trabalho.

\section{Breve revisão de literatura}

A cana-de-açúcar foi "introduzida em terras brasileiras nos primórdios do século XVI, com o objetivo de defender e alavancar sua colonização e, ao mesmo tempo, gerar divisas para a Coroa Portuguesa”, sendo que seu crescimento foi tão expressivo a ponto de caracterizar, entre 1530 e 1650, o ciclo do açúcar (Rissardi Júnior, 2015, p. 17).

A indústria açucareira, considerada moderna, surgiu no Brasil no século XIX. Em 1930 havia em operação no País 83 usinas produtoras de açúcar e álcool (Szmrecsányi, 1979). A agroindústria canavieira, no decorrer de sua trajetória, passou por várias fases e, para cada uma delas, houve políticas adotadas que buscaram dar suporte às atividades do setor (Tomasetto et al., 2013).

Focando mais no último quartel do século XX, em 1975 ocorreu a criação do Programa Nacional do Álcool (Proálcool), que foi uma política revolucionária para a agroindústria canavieira. Entre 1996/1997 e 2002/2003 houve o avanço da desregulamentação e a explicitação da fragilidade estrutural. Já entre 2003/2004 e 2012/2013, com a introdução do carro flex-fuel (2003), houve uma nova fase de crescimento da produção canavieira alavancada pela expansão da oferta de etanol, com aporte de Investimento Direto Estrangeiro no setor. Mesmo assim, uma das características desse momento foi a falta de planejamento, que seria evidenciada mais adiante.

Com efeito, o binômio crise e retrocessos marca os anos pós-2014, com queda da produção de cana e quebras de várias usinas/destilarias. O alto grau de endividamento e os equívocos de gestão, aliados à falta de planejamento e coordenação setorial, foram as principais causas desse cenário. Ademais, a política do governo de gerenciar artificialmente os preços de combustiveis fósseis, com o fito de controlar a inflação, desestimulou a política energética alternativa do etanol. De 2014/2015 a 2019/2020 a taxa de crescimento média da produção de cana-de-açúcar foi de somente $-0,5 \%$ a.a.

Destaca-se que em 2017 foi lançada outra medida com impacto no mercado de etanol. Trata-se do RenovaBio, uma política de combustíveis que entrou em vigor a partir de 2020, visando investimentos para o segmento alcooleiro no decurso de uma década (SNA-Sociedade Nacional da Agricultura, 2019). Sobre isto, Shikida e Cattelan (2020, p. 363) apontam que:

[...] foi instituída a Política Nacional de Biocombustíveis (RenovaBio), Lei no 13.576/2017, com intuito de promover a produção e o uso de biocombustiveis no Brasil, colaborando para a redução dos gases de efeito estufa e para o papel estratégico dos biocombustíveis na matriz energética (Brasil, 2017). Essa lei apontou para os produtores de cana-de-açúcar uma alternativa para expansão da produção de etanol, colaborando para a recuperação do setor. Desse modo, o RenovaBio é considerado 
o maior programa de descarbonização da matriz de transportes do mundo, contribuindo com os compromissos brasileiros firmados na redução de gases do efeito estufa em $43 \%$ até 2030.

Com o RenovaBio, vislumbra-se um cenário de redução da emissão de gás carbônico na atmosfera, mediante aumento da produção e consumo com a utilização de energias renováveis pelo mercado. Nesse cenário, os combustíveis verdes serão, $a$ priori, beneficiados, como o biodiesel e o etanol gerado a partir da cana-de-açúcar e também do milho (SNA-Sociedade Nacional da Agricultura, 2019).

Por outro lado, existe a Contribuição de Intervenção no Domínio Econômico (CIDE), instituída por meio da Lei 10.336/2001, cuja finalidade tem como propósito assegurar uma quantidade mínima de investimentos para infraestrutura de transporte, projetos ambientais ligados às indústrias de gás e petróleo, bem como subsidiar o transporte de álcool combustivel, e dos derivados de petróleo e gás natural (Ministério da Economia, 2021). No entanto, nos anos recentes a CIDE vem sendo utilizada no sentido de neutralizar os impactos gerados pelas mudanças de preços praticadas nas refinarias brasileiras, objetivando a contenção do aumento da inflação, devido que a oscilação decorrente da desses preços causa impacto direto no cálculo do Índice de Preços ao Consumidor Aplicado - IPCA (Tasca, 2014).

A agroindústria canavieira já viveu momentos de euforia produtiva ao longo de sua história, no entanto está em crise há pelo menos 8 anos. Considera-se que, além de seus custos de manutenção, os investimentos para que se possa instalar e colocar em funcionamento uma agroindústria canavieira são bastante elevados. Silva (2019), ao realçar que 96 unidades produtoras do setor sucroenergético no Brasil e de moagem de cana-de-açúcar encerraram suas atividades entre 2008 e 2015, ressalta que um dos fatores para essa situação crítica foi o aumento do custo de captação e restrições ao crédito.

Rodrigues e Rodrigues (2018), mediante caracterização do panorama econômicofinanceiro do setor sucroenergético no Brasil, a partir de dados de demonstrações financeiras de 150 usinas (para as safras 2014/2015 e 2015/2016), encontraram uma contundente heterogeneidade nesse setor. Foram encontrados nesse estudo quatro grupos distintos: um grupo que apresentou empresas com alta liquidez e baixo endividamento; dois grupos intermediários com empresas possuidoras de moderada alavancagem e liquidez, porém, com performances operacionais variando de alto a baixo; e o quarto grupo com empresas com alto endividamento, baixa liquidez e margens operacionais negativas.

Segundo informações da RPA Consultoria contidas em Novacana (2019b), a agroindústria canavieira vivencia uma crise no setor que está provocando sérios prejuízos. Esta Consultoria expõe que havia no Brasil, em 2019, um total de 444 agroindústrias canavieiras regulares, das quais 79 unidades (18\%) estavam enfrentando na justiça processo de recuperação judicial e, ainda, 27 defrontando-se com a lamentável situ- 
ação de falência (6\%). Todavia, outro agravante reforça um alerta para o setor, isto é, além das montas supracitadas, um contingente de mais de 20 unidades pretendiam, à época, iniciar um modelo de reorganização econômica para impedir sua falência.

No Estado do Paraná, cinco agroindústrias canavieiras com capacidade produtiva estão desativadas ou paradas, e destas, três não estão operando, enquanto duas encontram-se paradas (Infocana, 2018). Das agroindústrias canavieiras paranaenses em atividade, quatro passam por processo de recuperação judicial e uma, além de desativada, apresenta situação de falência via judicial (Novacana, 2018). A crise que atravessa a agroindústria canavieira paranaense não distingue porte das usinas, tanto que o maior grupo no estado, que detém o controle da Usina Santa Terezinha/Usacucar, entrou com pedido de recuperação judicial em 2019. "Recentemente, a Santa Terezinha realizou mudanças em sua estrutura de governança para profissionalizar sobretudo a gestão operacional. Alguns membros da família Meneghetti, dona da companhia, saíram da diretoria e executivos de mercado foram contratados" (MAIOR usina de cana-de-açúcar do Paraná..., 2019, s/p.).

Bechlin et al. (2020) salientaram o efeito perverso da crise do setor sucroenergético com relação ao fechamento de postos de trabalho. Nesse ínterim, Bernardelli et al. (2018) observaram que a atividade produtiva do cultivo de cana-de-açúcar foi a que mais reduziu o número de empregos no Estado do Paraná recentemente (passou de 13.402, em 2006, para 7.542 em 2016 - tendo como base de dados a Relação Anual de Informações Sociais/RAIS). Parte dessa redução se explica pela crescente mecanização do processo produtivo na cultura canavieira.

As razões da falência de uma agroindústria canavieira frequentemente estão associadas com crises macroeconômicas e/ou estratégias desacertadas por parte das firmas. Este trabalho procura inovar ao concatenar um estudo quantitativo com um qualitativo, onde se possa aferir, a partir de dados secundários, as consequências do malogro das usinas paranaenses sobre o Produto Interno Bruto (PIB) municipal; e depois fazer uma pesquisa de campo nas cidades onde as usinas falidas operavam, entrevistando agentes econômicos ligados, direta e indiretamente, com este contexto e que, portanto, tiveram experiências práticas com esse problema.

\section{Procedimentos metodológicos}

Este estudo pode ser classificado como explicativo, por buscar identificar e compreender os motivos e as consequências das falências de agroindústrias canavieiras no Estado do Paraná a partir de dois métodos: um quantitativo e outro qualitativo. A escolha desses dois métodos frisa-se, complementares, deu-se mediante necessidade de um maior aprofundamento do problema estudado, concomitante com uma base de resultados econométricos que reflitam a realidade do setor em análise. Ademais, conforme Minayo (2002) destaca, entre as pesquisas qualitativas e quantitativas não há supressões ou oposições, tendo sim interação dinâmica entre elas. 


\subsection{Abordagem quantitativa}

Em termos da pesquisa quantitativa, o escopo é de estimar e analisar, por procedimento econométrico, aspectos concernentes às agroindústrias canavieiras localizadas em cidades paranaenses em que essas unidades produtivas atuavam como forças motrizes e que faliram.

Para tanto, foram usados dados obtidos do Ministério do Trabalho e Emprego (MTEMinistério do Trabalho e do Emprego, 2021) via base de dados da RAIS e Classificação Nacional da Atividade Econômica (CNAE) do Instituto Nacional de Geografia e Estatística (IBGE, 2021). Foi realizado levantamento de dados do PIB real, Índice Firjan de Desenvolvimento Municipal (IFDM) - Educação e Emprego, área colhida (ha), quantidade de emprego formal na agricultura, quociente locacional na agricultura, média de anos de experiência/trabalho do trabalhador, gênero (percentual de participação da mão de obra masculina) e salário médio na agropecuária ${ }^{1}$. Cumpre dizer que algumas variáveis utilizadas foram inspiradas em estudos de Moraes (2007); Tschá et al. (2010); Dalchiavon e de Mello (2015) e Bastian et al. (2020).

Os dados coletados são referentes aos municípios com até 70 mil habitantes e que tiveram agroindústrias canavieiras instaladas e que vieram a falir entre os anos de 2007 a 2016. A escolha das localidades foi feita considerando o fato de que a agroindústria canavieira em estudo atuava como força motriz nesses municípios [Rolândia (66.580); Cambará (25.360); Engenheiro Beltrão (14.000); Porecatu (12.914); e Perobal (6.127 habitantes) (IBGE-Instituto Brasileiro de Geografia e Estatística, 2021)]. Destaca-se que para a análise dos dados foi aplicado logaritmo neperiano nas variáveis, com exceção do percentual de participação masculina e feminina, por terem comportamento de variável dummy. Após a estimação dos modelos lin-lin, log-log, linlog e log-lin, o modelo log-log apresentou melhor ajuste, de acordo com os critérios Akaike e Schwarz.

Neste trabalho foi utilizado o modelo econométrico com dados em painel, por proporcionar uma forma particular na disposição de dados, na qual cada unidade, indivíduo ou instituição é observado levando em consideração dois ou mais espaços de tempo. Outro ponto a destacar sobre esse modelo, é que possibilita maior eficiência quando o número de variáveis explicativas é reduzido.

No modelo econométrico de dados em painel é possivel estimar os critérios da regressão em conformidade com três distintos aspectos: dados empilhados (pooledregression), regressão com efeitos fixos e regressão com efeitos aleatórios. Após a identificação do modelo de melhor ajuste, é importante aplicar o teste de autocorrelação para constatar se há presença ou ausência de autocorrelação de observações

\footnotetext{
${ }^{1}$ Alguns desses dados, devido a sua característica monetária, foram deflacionados, quais sejam: salário médio na agropecuária e o PIB (variável dependente), passando a representar o salário médio real e PIB real. O deflator utilizado foi o Índice Geral de Preços (IGP-DI) da Fundação Getúlio Vargas (FGV). Também foi realizado o cálculo do Quociente Locacional (QL), que mostra como os ramos de atividades se comportam em determinado local e aponta também quais são os setores mais especializados em cada região, tendo uma macrorregião como referência para fins de comparação.
} 
ao longo do tempo, que no caso de séries transversais é possivel que ocorra omissão de variável importante (Wooldridge, 2010). Se observada correlação nos dados de corte transversal, denomina-se autocorrelação espacial, apresentando correlação condizente ao espaço e não ao longo do tempo. Para estimar a presença ou não de autocorrelação, deve-se atentar para que a ordenação dos dados tenha um interesse econômico e/ou alguma lógica (Gujarati e Porter, 2011).

Foi analisada ainda a presença ou ausência de heterocedasticidade, que pode decorrer como resultado de dados discrepantes (outliers), diferindo para muito mais ou para menos no que se refere às observações da amostra. Quando estas observações são inclusas ou exclusas, essencialmente se o tamanho da amostra diferir para menos, podem gerar alterações substanciais dos resultados da análise de regressão. A heterocedasticidade também pode surgir da assimetria na distribuição de um ou mais regressores que são inclusos no modelo (Gujarati e Porter, 2011).

Se o teste de heterocedasticidade rejeitou a hipótese nula de ausência de heterocedasticidade, enquanto o teste de autocorrelação aceitou a hipótese de ausência de autocorrelação, para dados em painel, no caso de identificação de autocorrelação e/ou heterocedasticidade nos modelos apresentados anteriormente, sugere-se como opção de correção desses problemas o modelo de dados em painel dinâmico.

Ao estudar o PIB deve-se considerar a possibilidade que este sofra ou não alterações no decorrer do tempo, ou seja, não se pode desprezar a hipótese de que esta variável se mantenha inalterada. Diante desse fato, o controle da estimação pelo fator dinâmico é determinante para a caracterização do modelo. Para um painel dinâmico, a variável dependente se apresenta defasada no vetor das variáveis explicativas, isto é, os níveis de atividades observadas, em um dado momento passado, tendem a exercer influência em níveis de atividades futuras (Blundell e Bond, 1998; Gama, 2013). A formalização deste modelo é representada pela Equação 1:

$$
\ln y_{i t}=\beta y_{i(t-1)}+\beta_{1} \ln X_{i t}+u_{i t}
$$

Sendo que $y_{i t}$ representa a variável dependente, o PIB; $y_{i(t-1)}$, a variável dependente com defasagem de um ano; $X$, o conjunto de variáveis explicativas; e $u$, o resíduo. Assume-se que no termo de erro estejam inclusos os efeitos específicos no PIB, $\eta_{i}$, e os choques aleatórios não observados ao longo do tempo, $\nu_{i t}$, conforme Equação 2.

$$
u_{i t}=\eta_{i}+\nu_{i t}
$$

Neste sentido, pode-se reescrever o modelo de dados em painel dinâmico conforme Equação 3: 


$$
\ln y_{i t}=\beta y_{i(t-1)}+\beta_{1} \ln X_{i t}+\eta_{1}+\nu_{i t} \quad|\beta|<1
$$

O termo de perturbação $\nu_{i t}$ apresenta média nula, acarretando que a esperança matemática seja zero, $E\left[\nu_{i t}\right]=E\left[\eta_{i}, \nu_{i t}\right]=0$ para $i=1,2,3, \ldots, N$ e para $t=1,2,3, \ldots, T$, então o erro não é autocorrelacionado. Assim, para expurgar os efeitos fixos sobre o PIB no decorrer do tempo, procede-se a uma transformação ao estimar o modelo. Para isso, primeiramente estima-se o modelo para remover os elementos que não variam no tempo, de acordo com a Equação 4.

$$
\ln y_{i t}-\ln y_{i(t-1)}=\beta\left[\ln y_{i(t-1)}-\ln y_{i(t-2)}\right]+\beta_{1}\left[\ln X_{i t}-\ln X_{i(t-1)}\right]+\left[\nu_{i t}-\nu_{i(t-1)}\right]
$$

Mesmo que a transformação realizada expurgue os efeitos fixos, ocorre também a verificação de viés ao especificar o modelo, visto que $\Delta y_{i(t-1)}$ e $\Delta \nu_{i t}$ são correlacionados. Faz-se necessário empregar variáveis instrumentais para o termo $\Delta l n y_{i(t-1)}$ e $\Delta \nu_{i t}$. Segundo Arellano e Bond (1991) e Gama (2013), para eliminar a correlação existente entre o termo transformado e a diferença da variável, deve-se usar variáveis dependentes defasadas $\sum_{j=2}^{j} \beta_{j} \ln y_{i(t-1)}$, ao menos em dois períodos.

\subsection{Abordagem qualitativa}

Neste trabalho a abordagem qualitativa se baseou em uma pesquisa de campo em que foram investigadas e analisadas as percepções de dez representantes dos setores públicos e privados, todos com forte conhecimento de causa no setor sucroenergético ligados, direta e indiretamente, com agroindústrias canavieiras paranaenses selecionadas que malograram, procurando entender não somente as causas desse panorama, como suas repercussões. Conforme já citado, as cidades paranaenses envolvidas foram: Cambará - onde operou a Usina Casquel; Engenheiro Beltrão - Sabarálcool/Matriz; Perobal - Sabarálcool/Filial; Porecatu - Central do Paraná; e Rolândia - Corol. Tais unidades atuavam como forças motrizes nesses municípios.

Foram realizadas pesquisas de campo no início de 2021, por meio de entrevistas com auxílio de um questionário (Quadro 1).

A seleção dos profissionais para responderem este instrumento de trabalho e, consequentemente, participarem das entrevistas, seguiu uma amostragem por tipicidade. Este tipo de amostragem não é probabilística, pois constitui-se em uma escolha intencional que, conforme Vergara (2007, p. 51), é "constituída pela seleção de elementos que o pesquisador considere representativos da população alvo”. Portanto, constituíram-se como pré-requisitos fundamentais para as escolhas dessas pessoas as suas expertises (de décadas, com base em informações prévias e existentes) ligadas, diretamente e indiretamente, com as agroindústrias canavieiras. 
Quadro 1. Questionário aplicado aos entrevistados na pesquisa de campo nos municípios de Cambará, Engenheiro Beltrão, Perobal, Porecatu e Rolândia (PR)

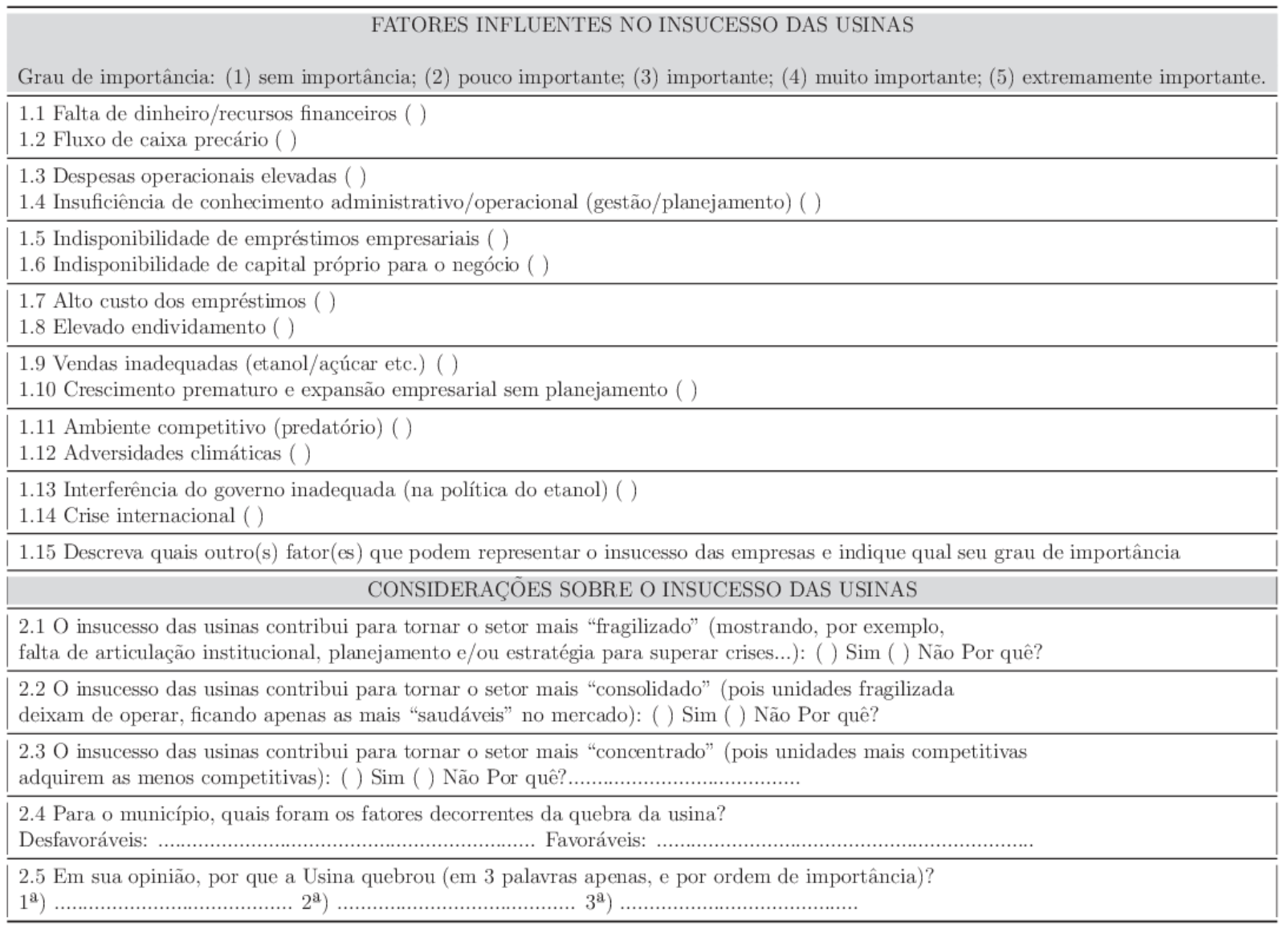

Fonte: Elaborado pelos autores.

Conforme exposto no Guadro 1, existem dois blocos de perguntas: sobre os fatores influentes no insucesso das usinas; e considerações sobre o insucesso dessas empresas. As informações que compõem esta amostra se fundamentam em entrevistas que procuraram extrair dos agentes econômicos envolvidos suas percepções sobre as causas e consequências das falências das unidades em análise. Ou seja, com esta pesquisa de campo, é possivel realizar um diálogo entre os resultados da abordagem quantitativa com a abordagem qualitativa, e vice-versa, maximizando a compreensão não somente das causas da falência de agroindústrias canavieiras, como também suas consequências.

Outrossim, como as amostragens não probabilísticas possuem uma linha tênue entre os critérios de um estudo e sua representatividade, para ampliar a percepção dos profissionais entrevistados, optou-se pela escolha de um representante do setor público de cada município (ou secretários da indústria/comércio, agricultura, planejamento/desenvolvimento ou outros representantes do poder público municipal) e de um representante do setor privado de cada município (ou diretores dos sindicatos rurais ou associações comerciais e industriais, representantes comerciais ou prestadores de serviço), que vivenciaram a falência das usinas nas suas respectivas 
localidades. Desta maneira, tanto a visão de mercado como a visão do setor público estão contidas na pesquisa qualitativa.

\section{Resultados e discussão}

\subsection{Abordagem quantitativa}

O primeiro modelo econométrico foi estimado pelo método de efeitos fixos, no qual o intercepto referente a cada indivíduo, $\beta_{i}$, não se altera com o tempo, porém, possa diferir entre os indivíduos, ou seja, é invariante em relação ao tempo (Gujarati e Porter, 2011). A fórmula que segue abaixo (Equação 5), demonstra como foi feita a aplicação do modelo de efeitos fixos na presente pesquisa.

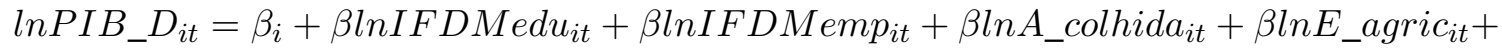

$$
\begin{aligned}
& \beta \operatorname{lnQL\_ agric} i t+\beta \ln \text { Exper }_{i t}+\beta \text { Homem }_{i t}+\beta \text { Mulher }_{i t}+\beta \operatorname{lnSMagrop} \text { Sit }_{1}+u_{i t}
\end{aligned}
$$

Sendo:

ln = logaritmo neperiano;

$P I B \_D=$ PIB real dos municípios;

IFDMedu = IFDM educação;

IF DMemp = IFDM emprego;

A_colhida = área colhida (em hectares);

$E \_a g r i c=$ quantidade de emprego formal na agricultura;

$Q L \_a g r i c=$ Quociente Locacional da agricultura;

Exper $=$ média de anos de experiência dos trabalhadores do município;

Homem = Percentual de participação da mão de obra masculina;

Mulher = Percentual de participação da mão de obra feminina;

SMagrop = Salário médio na agropecuária;

$u=$ termo de erro.

Para a escolha de qual modelo adotar, entre o de efeitos fixos e o de efeitos aleatórios, encontra-se a apuração de autocorrelação entre as variáveis explicativas com referência ao termo de erro. Já para decidir sobre qual dos modelos é o mais adequado, na realização da estimação dos parâmetros, trata-se da detecção de correlação entre a heterogeneidade não observada e as variáveis explicativas ao fazer o confronto das estimativas que se obteve referente a cada uma das abordagens (Wooldridge, 2010).

No modelo de efeitos aleatórios, uma hipótese de identificação é o fato da autocorrelação ser nula entre as variáveis explicativas relativamente ao efeito específico, considerando o termo de erro como sendo uma variável aleatória. Diante disso, o terceiro modelo estimado foi o de efeitos aleatórios. Para realizar o método de efeitos aleatórios utilizou-se a Equação 6: 


$$
\begin{aligned}
& \ln P I B \_D_{i t}=\beta_{i}+\beta \operatorname{lnIFDMedu} u_{i t}+\beta \operatorname{lnIFDMemp} p_{i t}+\beta \ln A \_c o l h i d a_{i t}+\beta \ln E \_a g r i c_{i t}+
\end{aligned}
$$

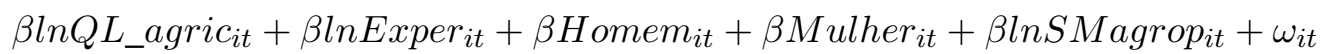

Se o modelo de efeitos aleatórios assume o $\beta_{i}$ como puramente aleatório e não algo imutável, ou seja, não tem correlação com os regressores, o modelo de efeitos fixos considera $\beta_{i}=0$. Isto demonstra que a diferença entre ambos consiste na relação entre a heterogeneidade não observada e as variáveis explicativas. No modelo de efeitos fixos pode-se fazer uma transformação que possibilita a remoção do efeito não observado antes da estimação, onde todas as variáveis explicativas relacionadas com o fator tempo são removidas. Já o estimador de efeitos aleatórios implica que o efeito não observado não tem correlação com todas as variáveis explicativas (Wooldridge, 2010).

Comparando-se os resultados do modelo de efeitos fixos com o de efeitos aleatórios, foi possível perceber a existência de diferenças substanciais entre ambos. Para determinar qual dos dois modelos deve ser escolhido, pode-se aplicar o teste de Hausman. No referido teste, a hipótese nula sugere que os estimadores do modelo de efeitos fixos e o modelo de componentes dos erros (MCE) não diferem. O teste de Hausman pode apresentar uma disposição assintótica $\chi^{2}$. Se a hipótese nula for rejeitada, concluise que o MCE não é apropriado pelo motivo de que os efeitos aleatórios podem estar correlacionados com um ou mais regressores, logo, o modelo de efeitos fixos seria preferivel (Gujarati e Porter, 2011).

Dessa forma, aplicou-se o teste de Hausman, cuja hipótese nula sugere que o modelo de efeitos aleatórios apresenta melhor ajuste. Caso $H_{0}$ seja rejeitada, então o modelo de efeitos fixos é preferível (Wooldridge, 2011). Como resultado, evidenciou-se que o teste não rejeitou $H_{0}$, portanto o modelo de melhor ajuste é o de efeitos aleatórios. Pela estatística do teste de Hausman, o modelo de efeitos aleatórios apresentou melhor ajuste do que o modelo de efeitos fixos para o presente estudo.

Na sequência, foi realizado o teste de autocorrelação para identificar se há presença ou ausência de correlação no modelo, a qual é definida por Gujarati e Porter (2011, p. 416) como: "correlação entre integrantes de séries de observações ordenadas no tempo [como as séries temporais] ou no espaço [como nos dados de corte transversal]". O teste de autocorrelação tem como hipótese nula que há ausência de autocorrelação no modelo. Como corolário, não foi rejeitada $H_{0}$, então não há presença de autocorrelação, consistindo em um bom resultado.

Por fim, aplicou-se o teste de heterocedasticidade de Wald modificado/aperfeiçoado, que tem como hipótese nula a ausência de heterocedasticidade. Quando uma observação difere com intensidade (muito maior ou muito menor) em relação às observações da amostra, considera-se como discrepante (outliers) (Gujarati e Porter, 2011). No teste efetuado neste estudo, houve rejeição de $H_{0}$, ou seja, houve heterocedastici- 
dade, que precisou ser corrigida.

Na sequência, a Tabela 1 mostra os resultados dos dados em painel dinâmico, pois foi o que apresentou melhor ajustamento. Cabe salientar que nos três primeiros modelos processados, o teste de Hausman apontou que o modelo mais adequado para o presente estudo foi o modelo de efeitos aleatórios, porém, este apresentou heterocedasticidade. Para corrigir esta heterocedasticidade foi aplicado o modelo de painel de dados dinâmico, resultando no melhor ajuste. Na Tabela 1, além dos resultados, tem-se também os coeficientes estimados de cada variável e os $p$-valores abaixo.

Tabela 1. Resultado da regressão do Modelo de Painel Dinâmico para os municípios de Cambará, Engenheiro Beltrão, Perobal, Porecatu e Rolândia (2007 a 2016)

\begin{tabular}{lccccccc}
\hline \hline Variáveis & Coef. & St.Err. & t-value & p-value & $\begin{array}{l}95 \% \\
\text { Conf. }\end{array}$ & Intervalo & Sig \\
\hline L.PIB_D & 0,465 & 0,126 & 3,69 & 0 & 0,218 & 0,712 & $* * *$ \\
IFDMedu & 0,477 & 0,253 & 1,88 & 0,06 & $-0,019$ & 0,974 & $*$ \\
IFDMemp & 0,148 & 0,089 & 1,66 & 0,098 & $-0,027$ & 0,322 & $*$ \\
A_colhida & 0,015 & 0,005 & 3,14 & 0,002 & 0,006 & 0,025 & $* * *$ \\
E_agric & $-0,121$ & 0,035 & $-3,41$ & 0,001 & $-0,19$ & $-0,051$ & $* * *$ \\
QL_agric & 0,108 & 0,048 & 2,24 & 0,025 & 0,013 & 0,203 & $* *$ \\
Exper & $-1,395$ & 0,719 & $-1,94$ & 0,052 & $-2,804$ & 0,014 & $*$ \\
Homem & $-0,85$ & 0,108 & $-7,87$ & 0 & $-1,061$ & $-0,638$ & $* * *$ \\
SMagrop & $-0,031$ & 0,027 & $-1,16$ & 0,247 & $-0,084$ & 0,021 & NS \\
\hline
\end{tabular}

Mean dependent var 5,716. SD dependent var 0,390

Number of obs 40 . Chi-square 1022,357

*** $\mathrm{p}<0,01 ;{ }^{* *} \mathrm{p}<0,05 ;{ }^{*} \mathrm{p}<0,1$

Fonte: Dados da pesquisa.

Nesta parte econométrica, vale lembrar, a variável dependente utilizada é o PIB dos municípios de Cambará, Engenheiro Beltrão, Perobal, Porecatu e Rolândia, procurando captar possíveis reflexos das falências das usinas no contexto macroeconômico municipal.

Sobre isto é importante destacar que a falência, especialmente em uma agroindústria canavieira, não é um fenômeno pontual, ou seja, a empresa está bem em um ano e no outro fali (a variável dummy para o ano de falência das usinas não foi significativa). Esse fenômeno é dinâmico (leva um certo tempo), razão pela qual os anos escolhidos foram de 2007 a 2016, ou seja, englobou tanto a crise financeira internacional de 2008, como a crise decorrente do represamento dos preços dos combustiveis fósseis que prejudicou o mercado do etanol durante o segundo governo Dilma (2011 e 2014). 
Dessa forma, procurou-se analisar o desempenho do PIB onde as usinas atuavam como forças motrizes, para captar possíveis reflexos dessas falências no contexto macroeconômico municipal, a partir de variáveis que permitam uma relação com o setor em estudo.

A partir do resultado do modelo de painel dinâmico, no tocante ao parâmetro estimado do PIB defasado (primeiro que aparece no modelo), cabe destacar que a geração do PIB no período passado tem influência na geração do PIB contemporâneo. Logo, a variação de $1 \%$ no PIB defasado de um período, induz uma variação de $0,465 \%$ no PIB contemporâneo - significativo a 1\% (Tabela 1).

Dando sequência aos resultados, pode-se observar que o IFDM educação apresentou relação direta em relação ao PIB (sendo significativa a 10\%). Isso expressa que a cada $1 \%$ de aumento do IFDM educação nos municípios, influenciou um crescimento médio no PIB de 0,477\%. Borges e Caetano (2016) ressaltam que a qualificação do trabalhador é um fator que, em geral, contribui para maior empregabilidade no competitivo mercado de trabalho. Para tanto, tornam-se importantes, seja em período de desemprego ou não, o investimento na educação formal e informal, nos cursos profissionalizantes, técnicos etc. Quanto à realidade das cinco cidades analisadas, devido à redução das atividades proporcionadas pelas agroindústrias canavieiras, os indivíduos que ali permaneceram buscaram maior qualificação exigida em outros segmentos da economia.

Para o diretor-presidente da Alcopar, Miguel R. Tranin, o que houve no setor sucroenergético, com o avanço da mecanização, foi que os trabalhadores mais novos “[...] estão no trator, estão na máquina. Fizeram cursos de treinamento para outras habilidades. Estão na indústria. Enfim, houve uma acomodação desse trabalhador na indústria e também nos municípios que estamos presentes" (UDOP-União dos Produtores de Bioenergia, 2020). Com efeito, ao se defrontar com a necessidade de buscar rendimentos em novas atividades, o trabalhador precisa atender aos requisitos condizentes com a realidade enfrentada, isso faz com que a educação seja o caminho adequado para esse fim.

Quanto ao IFDM emprego, constata-se que o mesmo tem relação direta e significativa a 10\%, ou seja, quando o nível de emprego aumenta em 1\%, o PIB cresce em torno de 0,148\%. Para Mattei (2018), a geração de postos de trabalho é uma das principais preocupações de políticas econômicas para o crescimento e melhoria do padrão de vida dos municípios brasileiros. Por meio deste resultado, a relação positiva entre emprego e PIB também foi observada para os cinco municípios.

Referente à área colhida, observa-se uma relação direta e significativa a 1\%, evidenciando que a cada $1 \%$ de aumento da área colhida, houve um crescimento médio no PIB de 0,015\%. Essa quase inexpressiva relação entre a área colhida e o PIB se justifica porque a fronteira agrícola paranaense, de modo geral, esgotou-se ainda no século XX. Logo, o que está ocorrendo no Paraná é uma mobilidade entre culturas, 
sendo que o pouco avanço que ocorreu nas cidades pesquisadas foi decorrente da entrada de cultivares em algumas áreas de pastagens. Conforme Alves e Assis (2001, p. 18), com as fronteiras agrícolas esgotadas no Paraná, “[...] a agricultura passou a expandir suas atividades através de substanciais realocações dos recursos produtivos entre culturas”. Nesse caso, houve opção dos agricultores pela expansão de área daquelas atividades agropecuárias mais estáveis e rentáveis.

Cabe considerar que o fechamento das usinas analisadas causou dois efeitos imediatos: ou a área de cana-de-açúcar plantada foi destinada para processamento industrial em uma outra unidade produtiva ativa; ou a área canavieira, antes destinada ao processamento industrial da unidade falida, tornou-se uma atividade agropecuária distinta. Isto ocorreu notadamente para a cultura de grãos (soja e milho), mas também ganhou certa expressão o segmento florestal, antes irrelevante no Paraná, mas que contabilizou, conforme Bastian et al. (2020), 5\% do Valor Bruto da Produção (VBP) Agropecuária estadual em 2017.

No que diz respeito aos empregos na agricultura (E_agric.), identifica-se uma relação inversa e significativa a $1 \%$. Assim sendo, nota-se que um aumento de $1 \%$ nesse tipo de emprego contribuiu para a redução média de 0,121\% no PIB. Um dos pontos que pode justificar a relação inversa apresentada é o fato dos municípios estudados terem passado por problemas decorrentes de falências de suas usinas, com diminuição considerável do número de trabalhadores formais nas atividades agrícolas. E ainda existe, conforme Bernardelli et al. (2018), a questão da mecanização do corte da cana, que reduziu a mão de obra no setor agrícola de forma intensa, mesmo antes da quebra das usinas.

Ademais, o trabalho urbano (comércio, por exemplo), mesmo sentindo os efeitos negativos da derrocada de uma indústria agrária cuja força motriz era expressiva, passou a ganhar maior expressão (relativa) diante do trabalho rural. Vale citar que no setor serviços existe, nessas cidades, uma parcela de funcionários públicos municipais, estaduais e federais que, com a falência ou não das usinas, contribuirá para manutenção do emprego não agrícola.

Mattei (2015) alerta para o comportamento recente do emprego agrícola no Brasil (2002 a 2013). Nesse período houve uma tendência de diminuição "[...] da participação do emprego agrícola no conjunto do emprego do País, exatamente no período em que o nível de ocupações nos demais setores de atividade econômica cresceu expressivamente na maioria deles"(Mattei, 2015, p. 41). Para esse autor, a agricultura não consegue absorver todo contingente populacional demandante de trabalho, devida elevada substituição da mão de obra pela força mecânica, em contexto de intenso processo de modernização agrícola que vem ocorrendo nesse setor. Concomitantemente, as pessoas do meio rural estão indo em busca de emprego no mercado urbano, o que afeta a dinâmica demográfica rural e também a urbana.

A agropecuária no Paraná, de modo geral, é considerada intensiva em capital, 
sendo o uso de máquinas e equipamentos um dos fatores que alavanca a produtividade desse setor, influenciando positivamente o seu VBP (Bastian et al., 2020). Não é sem fundamento que o estudo de Mattei (2015) apontou que as maiores reduções da participação do emprego agrícola, no conjunto das ocupações regionais, ocorreram no Sudeste e Sul. O Paraná reduziu consideravelmente a necessidade de mão de obra agrícola ao usar culturas, particularmente grãos (soja, milho e trigo sobretudo), que utilizam máquinas e equipamentos em todas as etapas do ciclo produtivo.

Assim, além dos fatores mencionados por Mattei (2015) e Bastian et al. (2020), nas cinco cidades em que a agroindústria canavieira atuava como força motriz, as falências afetaram, ainda mais, o já decrescente emprego agrícola local e, consequentemente, o PIB.

Concernente ao Quociente Locacional (QL) da agricultura, constata-se uma relação direta, com 5\% de significância, representando que quanto mais alto é o QL, mais especializada/concentrada é a atividade no município (em relação à respectiva microrregião). Em termos de elasticidade, a variação de $1 \%$ no $\mathrm{QL}$, induz um crescimento de $0,108 \%$ no PIB. Logo, quando as usinas encerraram suas atividades, a agricultura passou a ser menos concentrada (relativamente), deixando de focar em uma atividade específica. A busca por novos ramos de atuação visando suprir o desemprego causado pelo fechamento das usinas, as quais eram pontos de referência para o emprego da mão de obra de muitos trabalhadores, é uma explicação para esta relação.

Tschá et al. (2010) analisaram o encadeamento produtivo, localização e associação geográfica da agroindústria canavieira no Paraná, entre os anos de 1995 e 2005, portanto, antes das falências das cinco usinas estudadas. Conforme observaram, a localização e a associação geográfica dessa atividade no Norte do Paraná geraram encadeamentos e estimularam o processo de crescimento econômico regional, principalmente quando o setor sucroalcooleiro possuía um $Q L \geq 1$. Especificamente nas cinco cidades objeto deste estudo, o fechamento das usinas implicou, pela sua importância anterior, em redução considerável de empregos formais em suas localidades, e os efeitos, anteriormente positivos de encadeamento produtivo, localização e associação geográfica, passaram a ser negativos. O aspecto positivo desse cenário foi o município deixar de focar em uma atividade específica.

No tocante ao fator experiência, percebe-se uma relação inversa e significativa a $10 \%$, retratando que os anos de experiência do trabalhador por si só não são capazes de gerar mais produto. Logo, a variação de $1 \%$ no fator experiência, induz uma variação de $-1,395 \%$ no PIB (a única relação elástica e de maior magnitude constatada). $O$ dado encontrado sugere que as mudanças de profissões provocadas pela ocorrência do fechamento das usinas, fez com que o trabalhador entrasse em novas funções, porém, tendo menos tempo de experiência. A saída de trabalhadores das usinas, com mais experiência, foi constatada nas cidades visitadas durante a pesquisa de campo. Ademais, conforme o diretor-presidente da Alcopar, Miguel R. Tranin, os trabalhadores de cana, mormente os mais novos, buscaram outras atividades, “[...] os mais antigos, 
praticamente todos, nesse período, se aposentaram" (UDOP-União dos Produtores de Bioenergia, 2020).

O resultado quanto ao fator experiência, relacionando-se com o IFDM educação, traz uma relação aparentemente contraditória, ou seja, na medida em que o PIB subiu pelo aumento do IFDM educação, por outro lado o PIB diminuiu no período analisado em relação aos anos de experiência do trabalhador. Esta comparação é relevante porque a busca por maior educação para realização de novas atividades, fez com que a quantidade de anos de vivência prática fosse menor nessas funções, de modo que não é a experiência que contribuiu para o crescimento do PIB nas cidades supracitadas e, sim, a educação/capacitação.

Relativo à questão da participação percentual da mão de obra masculina, observase que existe uma relação inversa e significativa a 1\% (a cada 1\% de aumento da mão de obra masculina nos cinco municípios, induz uma diminuição média no PIB de -0,85\%). Como a maior participação de mão de obra nas agroindústrias canavieiras é masculina (Moraes, 2007; Costa et al., 2017), com o fechamento das usinas os homens foram os mais prejudicados com a perda do emprego no segmento sucroenergético, mesmo que estes fossem mais preferidos para o manuseio das máquinas. Dessa forma, a participação masculina no mercado de trabalho reduziu consideravelmente e a feminina aumentou (proporcionalmente e relativamente) após ocorrer o fim da ocupação laboral dessas usinas nos municípios estudados.

Este panorama da mão de obra masculina está relacionado com o que foi discutido para a questão dos empregos na agricultura (E_agric.). Portanto, deve-se levar em consideração que a mão de obra masculina, nesses cinco municípios estudados, foi muito impactada com o maior uso de máquinas e equipamentos em suas atividades agrícolas, e também com a falência das usinas.

No tocante ao salário médio na agropecuária, a relação com o PIB não gerou significância estatística.

Diante desses resultados, as contribuições da análise econométrica sugerem que o PIB dos municípios pesquisados, no âmbito geral, apresentou relação com o encerramento das atividades operacionais das agroindústrias canavieiras. As consequências decorrentes desse fenômeno mostraram contextos plausiveis com o quadro de falência ora retratado. Ou seja, as repercussões dessa derrocada alteraram, de certa forma, algumas variáveis relacionadas com o fechamento de agroindústrias canavieiras nos cinco municípios paranaenses foco do trabalho.

Não obstante, quais são as consequências dessa falência a partir da percepção dos agentes econômicos municipais ligados, direta e indiretamente, com essas unidades agroindustriais que deixaram de funcionar? A abordagem qualitativa, na próxima subseção, procura entender não somente as causas desse quadro (corroborando ou não, algumas relações encontradas na análise quantitativa), como também suas repercussões mediante a aplicação de questionário/entrevistas. 


\subsection{Abordagem qualitativa}

Conforme salientado, a aplicação de questionários, seguido de entrevistas, foi realizada no início do ano de 2021 nas cinco cidades objetos deste estudo. Para a visitação houve a presença in loco do pesquisador. Faz-se necessário realçar que, mesmo em período de pandemia, todos os cuidados de manutenção da distância, uso de máscara e álcool gel foram observados. O percurso feito pelo pesquisador, em uma semana intensa de trabalho, foi de $1.581 \mathrm{~km}$.

Nas cidades visitadas foram realizados contatos prévios com pessoas/instituições (junto aos membros da comunidade local de reputação e história de vida na região), tanto do setor público como do setor privado, que pudessem indicar profissionais com expertises de décadas ligadas, diretamente e indiretamente, com a temática falência das agroindústrias canavieiras locais. Um ponto de corte para entrevistar tais pessoas, além dessa indicação prévia, era o seu conhecimento na atividade em que atuou (alguns já eram aposentados no momento da pesquisa, mas atuaram no período de funcionamento da usina) ou atua de, no mínimo, 25 anos de prática. A média de anos das dez pessoas entrevistadas, no tocante ao conhecimento demandado, foi de aproximadamente 30 anos. Isto denota a seriedade nos critérios dessa amostra por tipicidade que, ainda não sendo aleatória, favoreceu a representatividade no estudo.

Ressalta-se que após a abordagem inicial para explicação do teor do estudo, o questionário era entregue ao entrevistado. Ao respondê-lo, esse podia tecer comentários sobre a falência da usina ocorrida na sua localidade, fazendo do questionário também um norte para a entrevista, onde algumas informações foram além das indagações postas. Isto permitiu maior interação entre o pesquisador e os entrevistados, possibilitando profícuas conversas. Esta é a razão de não ter optado pela entrevista de forma remota, devido exatamente a maior interatividade que o contato pessoal possibilitou.

Destarte, foram entrevistados dez profissionais, cujos resultados dos fatores influentes no insucesso das usinas estão sintetizados na Quadro 2. Observando as áreas sombreadas desta Tabela, constata-se que no total geral dos pesquisados, considerando os maiores percentuais de ocorrências (em que não houve empate entre as alternativas de gradação), os itens considerados "extremamente importantes" para o insucesso das agroindústrias canavieiras foram: falta de dinheiro/recursos financeiros (60\%); fluxo de caixa precário (60\%); insuficiência de conhecimento administrativo/operacional (60\%); elevado endividamento (70\%); crescimento prematuro e expansão empresarial sem planejamento (50\%). Ao revés, considerando os itens "pouco importantes" para a falência das agroindústrias canavieiras, novamente ressaltando os maiores percentuais de ocorrências (em que não houve empate entre as alternativas de gradação), no total geral dos pesquisados houve apenas o apontamento para ambiente competitivo (40\%) e adversidades climáticas (50\%). 


\section{Quadro 2. Resultado dos fatores influentes no insucesso das usinas conforme entre- vistados nos municípios de Cambará, Engenheiro Beltrão, Perobal, Porecatu e Rolân- dia (PR)}

\begin{tabular}{|c|c|c|c|c|c|}
\hline \multirow{2}{*}{ Questão 1.1} & \multicolumn{5}{|c|}{ Falta de dinheiro/recursos financeiros (\%) } \\
\hline & Sem importância & Pouco importante & Importante & Muito importante & Extremamente importante \\
\hline Representantes pesquisados do Setor Público & - & - & 20 & - & 80 \\
\hline Representantes pesquisados do Setor Privado & - & - & 40 & 20 & 40 \\
\hline Total Geral dos pesquisados & - & - & 30 & 10 & 60 \\
\hline \multirow{2}{*}{ Questão 1.2} & \multicolumn{5}{|c|}{ Fluxo de caixa precário (\%) } \\
\hline & Sem importância & Pouco importante & Importante & Muito importante & Extremamente importante \\
\hline Representantes pesquisados do Setor Público & - & - & - & 60 & 40 \\
\hline Representantes pesquisados do Setor Privado & - & 20 & - & - & 80 \\
\hline Total Geral dos pesquisados & - & 10 & - & 30 & 60 \\
\hline \multirow{2}{*}{ Questão 1.3} & \multicolumn{5}{|c|}{ Despesas operacionais elevadas (\%) } \\
\hline & Sem importância & Pouco importante & Importante & Muito importante & Extremamente importante \\
\hline Representantes pesquisados do Setor Público & - & - & 20 & 40 & 40 \\
\hline Representantes pesquisados do Setor Privado & - & - & 40 & 40 & 20 \\
\hline Total Geral dos pesquisados & - & - & 30 & 40 & 30 \\
\hline \multirow{2}{*}{ Questão 1.4} & \multicolumn{5}{|c|}{ Insuficiência de conhecimento administrativo/operacional (gestão e planejamento) (\%) } \\
\hline & Sem importância & Pouco importante & Importante & Muito importante & Extremamente importante \\
\hline Representantes pesquisados do Setor Público & 20 & - & 20 & 40 & 20 \\
\hline Representantes pesquisados do Setor Privado & - & - & - & - & 100 \\
\hline Total Geral dos pesquisados & 10 & - & 10 & \begin{tabular}{|l|}
20 \\
\end{tabular} & 60 \\
\hline \multirow{2}{*}{ Questão 1.5} & \multicolumn{5}{|c|}{ Indisponibilidade de empréstimos empresariais (\%) } \\
\hline & Sem importância & Pouco importante & Importante & Muito importante & Extremamente importante \\
\hline Representantes pesquisados do Setor Público & 20 & - & 40 & 40 & - \\
\hline Representantes pesquisados do Setor Privado & 20 & 20 & 40 & - & 20 \\
\hline Total Geral dos pesquisados & 20 & 10 & 40 & 20 & 10 \\
\hline \multirow{2}{*}{ Questão 1.6} & & Indisponibilid & ade de capit & al próprio para o 1 & ócio (\%) \\
\hline & Sem importância & Pouco importante & Importante & Muito importante & Extremamente importante \\
\hline Representantes pesquisados do Setor Público & 20 & 20 & 20 & 20 & 20 \\
\hline Representantes pesquisados do Setor Privado & - & - & 40 & 20 & 40 \\
\hline Total Geral dos pesquisados & 10 & 10 & 30 & \begin{tabular}{|l|}
20 \\
\end{tabular} & 30 \\
\hline & & & to custo dos & empréstimos (\%) & \\
\hline Questao 1.7 & Sem importância & Pouco importante & Importante & Muito importante & Extremamente importante \\
\hline Representantes pesquisados do Setor Público & - & 40 & - & 20 & 40 \\
\hline Representantes pesquisados do Setor Privado & - & 20 & 60 & - & 20 \\
\hline Total Geral dos pesquisados & - & 30 & 30 & 10 & 30 \\
\hline Ouestão 18 & & & Elevado end & ividamento (\%) & \\
\hline Questado 1.0 & Sem importância & Pouco importante & Importante & Muito importante & Extremamente importante \\
\hline Representantes pesquisados do Setor Público & - & - & 20 & 20 & 60 \\
\hline Representantes pesquisados do Setor Privado & - & - & 20 & - & 80 \\
\hline Total Geral dos pesquisados & - & - & 20 & 10 & 70 \\
\hline & Vendas inadequ & adas (etanol/açúc & ar e demais & produtos e subpro & itos da cana-de-açúcar) (\%) \\
\hline Questao 1.9 & Sem importância & Pouco importante & Importante & Muito importante & Extremamente importante \\
\hline Representantes pesquisados do Setor Público & 20 & 20 & 60 & - & - \\
\hline Representantes pesquisados do Setor Privado & 20 & - & 20 & 40 & 20 \\
\hline Total Geral dos pesquisados & 20 & 10 & 40 & 20 & 10 \\
\hline 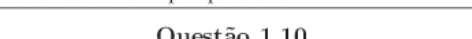 & Cres & cimento prematu & ro e expansã & o empresarial sem & lanejamento (\%) \\
\hline Questao 1.10 & Sem importância & Pouco importante & Importante & Muito importante & Extremamente importante \\
\hline Representantes pesquisados do Setor Público & 40 & 20 & 20 & 20 & - \\
\hline Representantes pesquisados do Setor Privado & - & - & - & - & 100 \\
\hline Total Geral dos pesquisados & 20 & 10 & 10 & 10 & 50 \\
\hline Ouestão 111 & & Ambie & nte competi & tivo (predatório) & \\
\hline Questao 1.11 & Sem importância & Pouco importante & Importante & Muito importante & Extremamente importante \\
\hline Representantes pesquisados do Setor Público & 20 & 40 & 40 & - & - \\
\hline Representantes pesquisados do Setor Privado & - & 40 & 20 & 40 & - \\
\hline Total Geral dos pesquisados & 10 & 40 & 30 & 20 & - \\
\hline Ouestão 12 & & & Adversidade: & climáticas (\%) & \\
\hline Questao 1.12 & Sem importância & Pouco importante & Importante & Muito importante & Extremamente importante \\
\hline Representantes pesquisados do Setor Público & 20 & 80 & - & - & - \\
\hline Representantes pesquisados do Setor Privado & 40 & 20 & 20 & - & 20 \\
\hline Total Geral dos pesquisados & 30 & 50 & 10 & - & 10 \\
\hline & & nterferência do go & verno inade & quada (na política & etanol) $(\%)$ \\
\hline Questao 1.13 & Sem importância & Pouco importante & Importante & Muito importante & Extremamente importante \\
\hline Representantes pesquisados do Setor Público & - & 40 & 40 & - & 20 \\
\hline Representantes pesquisados do Setor Privado & 20 & - & 40 & 20 & 20 \\
\hline Total Geral dos pesquisados & 10 & 20 & 40 & 10 & 20 \\
\hline Ouestão 114 & & & Crise inter & nacional (\%) & \\
\hline & Sem importância & Pouco importante & Importante & Muito importante & Extremamente importante \\
\hline Representantes pesquisados do Setor Público & 20 & 40 & 20 & 20 & - \\
\hline Representantes pesquisados do Setor Privado & - & 20 & 60 & 20 & - \\
\hline Total Geral dos pesquisados & 10 & 30 & 40 & 20 & - \\
\hline
\end{tabular}

Fonte: Dados da Pesquisa.

Obs.: As áreas sombreadas denotam os maiores \% de ocorrência: cor amarela (para total geral dos pesquisados), lilás (para pesquisados do setor público) e verde (para pesquisados do setor privado). 
De forma geral, os apontamentos dos pesquisados no tocante à gradação "extremamente importantes" para o malogro das agroindústrias canavieiras, vão ao encontro com o que citaram Bernardo et al. (2018), Cruz et al. (2019), Novacana (2019a), Bechlin et al. (2020) e Goebel et al. (2020), em estudos que abrangeram também o tema falência no setor sucroenergético. Porém, a inovação deste artigo está no nível de importância que os agentes pesquisados deram para cada item. Além disso, no Paraná, o ambiente competitivo e as adversidades climáticas foram considerados pouco importantes para justificar a quebra de uma usina.

Em se tratando dos respondentes do setor público, considerando o maior percentual de ocorrência (mantendo o pressuposto de não ocorrer empate entre as alternativas de gradação), os motivos para a falência das agroindústrias canavieiras apontados foram: falta de dinheiro/recursos financeiros (80\%); fluxo de caixa precário (60\%); insuficiência de conhecimento administrativo/operacional (40\%); elevado endividamento (60\%); vendas inadequadas (60\%); crescimento prematuro e expansão empresarial sem planejamento (40\%); adversidades climáticas (80\%) e crise internacional (40\%).

Contudo, realça-se que as gradações das respostas para os percentuais de maiores ocorrências do setor público mencionadas, foram mais dispersas em termos de gradação, variando desde o item "sem importância” (crescimento prematuro e expansão empresarial sem planejamento); passando pelo item "pouco importante" (adversidades climáticas e crise internacional); "importante" (vendas inadequadas); "muito importante" (fluxo de caixa precário e insuficiência de conhecimento administrativo/operacional); completando com o item "extremamente importante" (falta de dinheiro/recursos financeiros e elevado endividamento).

De forma análoga, para o caso dos respondentes do setor privado, os motivos mais expressivos para o insucesso das agroindústrias canavieiras em termos percentuais foram: fluxo de caixa precário (80\%); insuficiência de conhecimento administrativo/operacional (100\%); indisponibilidade de empréstimos empresariais (40\%); alto custo dos empréstimos (60\%); elevado endividamento (80\%); vendas inadequadas (40\%); crescimento prematuro e expansão empresarial sem planejamento (100\%); adversidades climáticas (40\%); interferência do governo inadequada (40\%); e crise internacional (60\%).

Desta vez, para os respondentes do setor privado, as gradações das respostas foram menos dispersas em relação ao setor público. O item "sem importância" está relacionado com as adversidades climáticas; "importante" com indisponibilidade de empréstimos empresariais, alto custo dos empréstimos, interferência do governo inadequada e crise internacional; "muito importante" com vendas inadequadas; e "extremamente importante" com fluxo de caixa precário, insuficiência de conhecimento administrativo/operacional, elevado endividamento, crescimento prematuro e expansão empresarial sem planejamento. 
Os dois únicos fatores influentes no insucesso das usinas que somaram 100\% nas respostas, portanto unanimidade, foram a insuficiência de conhecimento administrativo/operacional (gestão e planejamento) e crescimento prematuro e expansão empresarial sem planejamento, apontadas pelos respondentes do setor privado. Novamente, tal assertiva corrobora muito do que foi salientado por Bernardo et al. (2018), Cruz et al. (2019), Novacana (2019a), Bechlin et al. (2020) e Goebel et al. (2020). Empresas de Consultoria, como a RPA, também apontam estas variáveis citando o termo "erros de gestão” (Ramos, 2017). Nesse cenário, não é sem razão que algumas empresas do setor sucroenergético se mantiveram no mercado, enquanto outras malograram. As crises e as adversidades climáticas, por exemplo, foram para todas, as estratégias para superação das dificuldades e/ou expansão é que fizeram a diferença.

Isto posto, a Tabela 2 expõe os resultados das considerações sobre o insucesso das usinas, conforme entrevistados nos municípios de Cambará, Engenheiro Beltrão, Perobal, Porecatu e Rolândia (PR). Para o total geral dos pesquisados, o insucesso das usinas contribui para que o segmento se torne mais fragilizado e mais consolidado, segundo $70 \%$ dos entrevistados. Na sequência, todos os entrevistados concordaram que o segmento se torna mais concentrado, onde as unidades que atuam com maior competitividade têm capacidade de adquirir as que não demonstram o mesmo desempenho. Cabe salientar, no cotejo entre os representantes do setor público e setor privado, nas questões 2.1 e 2.2 da Tabela 2 , a menor dispersão dos entrevistados do setor privado, que foram praticamente unânimes em referendar que o insucesso das usinas contribui para tornar o setor mais "fragilizado" e mais "consolidado".

Já para os municípios (item 2.4), segundo indicado pelos representantes dos setores entrevistados, os principais fatores desfavoráveis decorrentes da quebra da usina foram o desemprego, queda da renda e da arrecadação dos municípios. Quanto aos fatores favoráveis, os respondentes do setor público fizeram mais apontamentos como, por exemplo, abertura para o cultivo de grãos e expansão para outras atividades do agronegócio. Neste tocante, um entrevistado do setor privado pontuou como fator favorável decorrente das quebras de usinas a descentralização da renda.

Embora não tenha sido realçado na Tabela 2, constatou-se em pesquisa de campo com vários agentes entrevistados, que as usinas ao falirem não cumpriram seus compromissos financeiros com parte de seus credores (fornecedores de cana, empresas de insumos etc.). Gitman (2010) salientou que uma organização, ao encerrar suas atividades, pode vir a não cumprir seus compromissos com terceiros. Isto foi uma tônica observada em todas as cidades visitadas durante este trabalho.

Finalizando os questionamentos da Tabela 2 (item 2.5), os respondentes mencionaram, em ordem de importância, as três causas fundamentais para que as agroindústrias canavieiras viessem a falir, constatando-se que a causa fundamental determinante da falência foi falta de gestão. Embora outras especificações não foram expressas como "gestão", fazem parte do seu contexto, ou seja, falta de planejamento/controle, fluxo de caixa precário, negociação, políticas, desvirtuamento das funções e 
Tabela 2. Resultado das considerações sobre o insucesso das usinas conforme entrevistados nos municípios de Cambará, Engenheiro Beltrão, Perobal, Porecatu e Rolândia (PR)

\begin{tabular}{|c|c|c|c|c|c|c|c|c|c|c|c|}
\hline \multirow{2}{*}{\multicolumn{2}{|c|}{ Questões }} & \multicolumn{3}{|c|}{$\begin{array}{l}\text { Representantes } \\
\text { pesquisados do } \\
\text { Setor Público }\end{array}$} & \multicolumn{2}{|c|}{$\begin{array}{l}\text { Representantes } \\
\text { pesquisados do } \\
\text { Setor Privado }\end{array}$} & \multicolumn{5}{|c|}{$\begin{array}{l}\text { Total Geral dos } \\
\text { pesquisados }\end{array}$} \\
\hline & & \multicolumn{2}{|c|}{ Sim (\%) } & Não (\%) & Sim (\%) & $\begin{array}{l}\text { Privado } \\
\text { Não (\%) }\end{array}$ & Sim $(\%)$ & \multicolumn{4}{|c|}{ Não (\%) } \\
\hline \multicolumn{2}{|c|}{$\begin{array}{l}2.1 \mathrm{O} \text { insucesso das usinas contribui para tornar o setor mais } \\
\text { "fragilizado"(mostrando, e.g. falta de articulação institucional, } \\
\text { planejamento e/ou estratégia para superar crises...) }\end{array}$} & \multicolumn{2}{|c|}{40} & 60 & 100 & - & 70 & \multicolumn{4}{|c|}{30} \\
\hline \multicolumn{2}{|c|}{$\begin{array}{l}2.2 \text { O insucesso das usinas contribui para tornar o setor mais } \\
\text { "consolidado" (pois unidades fragilizadas deixam de operar, } \\
\text { ficando apenas as mais "saudáveis" no mercado) }\end{array}$} & \multicolumn{2}{|c|}{60} & 40 & 80 & 20 & 70 & \multicolumn{4}{|c|}{30} \\
\hline \multicolumn{2}{|c|}{$\begin{array}{l}2.3 \text { O insucesso das usinas contribui para tornar o setor mais } \\
\text { "concentrado" (pois unidades mais competitivas adquirem as } \\
\text { menos competitivas)? }\end{array}$} & \multicolumn{2}{|c|}{100} & 10 & 100 & - & 100 & \multicolumn{4}{|c|}{ - } \\
\hline \multirow{2}{*}{$\begin{array}{l}\text { 2.4 Para o município, quais foram os } \\
\text { fatores decorrentes da quebra da usina? }\end{array}$} & \multicolumn{6}{|c|}{ Fatores desfavoráveis } & & & Fator & es favorávei & \\
\hline & Setor $\mathrm{Pr}$ & blico & & Setor & Priva & ado & & tor Públic & & Seto & r Privado \\
\hline Respondente 1 & $\begin{array}{r}\text { Desempreg } \\
\text { da arrece }\end{array}$ & $\begin{array}{l}\text { o/que } \\
\text { diçãc }\end{array}$ & & & - & & & - & & & - \\
\hline Respondente 2 & - & & & Dese & mpre & & & - & & & - \\
\hline Respondente 3 & $\begin{array}{r}\text { Desempreg } \\
\text { para o co }\end{array}$ & $\begin{array}{l}\text { o/per } \\
\text { mérci }\end{array}$ & & & - & & $\begin{array}{r}\mathrm{Abr} \\
\mathrm{P}\end{array}$ & $\begin{array}{l}\text { iu mais ár } \\
\text { para grãos }\end{array}$ & & & - \\
\hline Respondente 4 & - & & & $\begin{array}{r}\text { Desempre } \\
\text { arrecadaç } \\
\mathrm{r}\end{array}$ & $\begin{array}{l}\text { go/q } \\
\text { ào/q } \\
\text { nda }\end{array}$ & ueda da & & - & & & - \\
\hline Respondente 5 & $\begin{array}{r}\text { Desempreg } \\
\text { da arrece }\end{array}$ & o/que & & & - & & & iu mais ár & & & - \\
\hline Respondente 6 & - & & & Dese & $\mathrm{mpre}$ & & & - & & & - \\
\hline Respondente 7 & Queda de & rend & & & - & & & - & & & - \\
\hline Respondente 8 & - & & & $\begin{array}{r}\text { Queda da } 1 \\
\text { arrecadação } \\
\text { mais in }\end{array}$ & $\begin{array}{l}\text { opul } \\
\text { /não } \\
\text { lustr }\end{array}$ & $\begin{array}{l}\text { lação e da } \\
\text { consegue } \\
\text { ializar }\end{array}$ & & - & & & - \\
\hline Respondente 9 & $\begin{array}{r}\text { Desempre } \\
\text { financei } \\
\text { agricul }\end{array}$ & $\begin{array}{l}\text { so/cri } \\
\text { a dos } \\
\text { ores }\end{array}$ & & & - & & $\begin{array}{r}\text { Abr } \\
\text { para }\end{array}$ & $\begin{array}{l}\text { iu mais ár } \\
\text { o agroneg }\end{array}$ & $\begin{array}{l}\text { eas } \\
\text { Sócio }\end{array}$ & & - \\
\hline Respondente 10 & 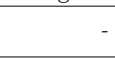 & & & $\begin{array}{r}\text { Desemp } \\
\text { da arr } \\
\end{array}$ & ego/ & $\begin{array}{l}\text { queda } \\
\text { ação }\end{array}$ & & - & & $\begin{array}{r}\text { Desce } \\
\text { da }\end{array}$ & $\begin{array}{l}\text { ntralização } \\
\text { renda }\end{array}$ \\
\hline 2.5 Em sua opinião, por que a Usina quebrou (em & & & & etor Público & & & & & & or Privado & \\
\hline 3 palavras apenas, e por ordem de importância)? & $1^{\mathrm{a}}$ & & & $2^{\mathrm{a}}$ & & $3^{\mathrm{a}}$ & & $1^{\mathrm{a}}$ & & $2^{\mathrm{a}}$ & $3^{\mathrm{a}}$ \\
\hline Respondente 1 & Faltou ges & & & $\begin{array}{l}\text { svirtuamento } \\
\text { las funções }\end{array}$ & & $\begin{array}{l}\text { sirtuamento } \\
\text { os recursos }\end{array}$ & & - & & - & - \\
\hline Respondente 2 & - & & & - & & - & Faltc & u gestão & Adn & n. familiar & Faltou política \\
\hline Respondente 3 & $\begin{array}{r}\text { Faltou } \\
\text { valorizaç } \\
\text { do colabor }\end{array}$ & & $\begin{array}{l}\text { Falt } \\
\text { recu }\end{array}$ & $\begin{array}{l}\text { tou dinheiro/ } \\
\text { ursos públicos }\end{array}$ & & ltou política & & - & & - & $e_{1}$ \\
\hline Respondente 4 & - & & & - & & - & $\begin{array}{r}\mathrm{F} \\
\text { plan }\end{array}$ & $\begin{array}{l}\text { altou } \\
\text { ejamento }\end{array}$ & & $\begin{array}{l}\text { Baixa } \\
\text { dutividade } \\
\text { le cana }\end{array}$ & $\begin{array}{l}\text { Fluxo de caixa } \\
\text { precário }\end{array}$ \\
\hline Respondente 5 & Faltou ges & & & $\begin{array}{l}\text { altou capital } \\
\text { de giro }\end{array}$ & Fal & tou controle & & - & & - & - \\
\hline Respondente 6 & - & & & - & & - & Faltc & u gestão & Falt & u dinheiro & Faltou controle \\
\hline Respondente 7 & $\begin{array}{r}\text { Faltou } \\
\text { capital pró }\end{array}$ & prio & & altou gestão & & $\begin{array}{l}\text { Desvio de } \\
\text { objetivo }\end{array}$ & & o & & - & - \\
\hline Respondente 8 & $\begin{array}{llll}1 & 1 \\
\end{array}$ & & & - & & - & Faltc & u gestão & $\begin{array}{l}\text { Alta } \\
\text { entr }\end{array}$ & $\begin{array}{l}\text { competição } \\
\text { as usinas }\end{array}$ & $\begin{array}{c}\text { Avesso à } \\
\text { modernização }\end{array}$ \\
\hline Respondente 9 & Faltou ges & & & $\begin{array}{l}\text { Faltou } \\
\text { negociação }\end{array}$ & & $\begin{array}{l}\text { Faltou } \\
\text { odernização }\end{array}$ & & - & & - & - \\
\hline Respondente 10 & - & & & - & & - & Faltc & u gestão & Falt & tou gestão & Faltou gestão \\
\hline
\end{tabular}

Fonte: Dados da Pesquisa (2021).

recursos, desvio de objetivo e ser avesso à modernização.

No geral, evidencia-se que a maior dificuldade das agroindústrias canavieiras falidas esteve atrelada com a fragilidade dos gestores na condução de seus negócios. Dessa forma, estes resultados sobre as considerações do insucesso das usinas corroboram com os resultados discutidos a partir dos fatores influentes no insucesso das usinas e suas gradações (Tabela ??), bem como dialoga com estudos realizados para o setor sucroenergético sobre o tema em questão.

Não é sem razão que foi citado na revisão de literatura que o maior grupo produtor de açúcar e álcool no Paraná (Santa Terezinha/Usacucar), que está em recuperação judicial desde 2019, realizou mudanças em sua estrutura de governança buscando, mormente, profissionalizar sua gestão operacional, contratando executivos de mercado e afastando membros da família da administração (MAIOR usina de cana-de- 
açúcar do Paraná..., 2019). Paulino e Rossi (2003) dizem que o sucesso ou insucesso das organizações, com frequência, estão relacionados com as peculiaridades intrínsecas dos empreendedores que as conduzem. Para Pereira e Santos (1995), os aspectos de grande influência para a derrocada das organizações são: inexperiência e incompetência para a gestão empresarial.

Como corolário da análise dos resultados do estudo quantitativo, comparando alguns dos apontamentos feitos pelos entrevistados, corrobora-se a lógica de algumas variáveis que resultaram em explicativas para o desempenho do PIB nos cinco municípios visitados. Quando vários respondentes apontaram, por exemplo, que a derrocada das usinas abriu espaço para outras atividades, isto está relacionado com o QL na análise econométrica. Ou seja, quando as usinas faliram, a agricultura passou a ser menos concentrada (relativamente), deixando de focar em uma atividade específica. A redução de postos de trabalho que ocorreu, sobretudo no mercado masculino nessas localidades, também foi um apontamento que relaciona diretamente os resultados da análise econométrica com a percepção dos entrevistados. Com efeito, praticamente todos os entrevistados foram unânimes em referendar que houve queda de empregos na agricultura, principalmente no tocante à mão de obra masculina, preponderante em agroindústrias canavieiras.

Complementarmente, a incorporação de uma análise do posicionamento conjuntural das unidades produtivas pesquisadas, antes e no encerramento de atividades, evidencia a perda de posição relativa que as cinco usinas tiveram ao longo do tempo. Tomando como parâmetro a safra 2000/2001, sendo 16 grupos de usinas operando, a Central do Paraná moeu 1.548.830 toneladas de cana (a $3^{\text {a }}$ maior produção desse grupo, com $8 \%$ da participação canavieira estadual), antes de falir era a $10^{\mathrm{a}}$ produção, com 2,8\% da participação estadual. O Grupo Sabarálcool moeu 1.117.806 toneladas de cana (a $5^{\mathbf{a}}$ maior produção, com $5,8 \%$ da participação estadual), antes de falir era a 7ª produção, com 4,2\% da participação estadual. A Corol moeu 542.883 toneladas de cana (a $11^{\underline{a}}$ produção, com $2,8 \%$ da participação estadual), antes de falir era a $14^{\underline{a}}$ produção, com 1,9\% da participação estadual. A Casquel moeu 230.000 toneladas de cana (a 15 $5^{\underline{a}}$ produção, com 1,2\% da participação estadual), antes de falir era a menor produção no Paraná, com os mesmos 1,2\% de participação) (Graef et al., 2016). Deduz-se que essa bancarrota atingiu pequena, média e grande usina.

Assim, observa-se a relevância de um trabalho que não somente utilizou dados secundários, mas também dados primários, concatenando resultados que, em uma ou outra metodologia apenas, ficaria incompleta.

\section{Conclusões}

Este estudo procurou evidenciar e analisar quais os motivos e consequências da falência de agroindústrias canavieiras no Estado do Paraná. Para tanto, foram utilizadas duas abordagens metodológicas concatenadas entre si, uma quantitativa e outra 
qualitativa.

Com o método quantitativo, o instrumental econométrico mais apropriado para análise foi o modelo de dados em painel dinâmico, buscando verificar como se comportou o PIB de cinco cidades paranaenses (Cambará, Engenheiro Beltrão, Perobal, Porecatu e Rolândia), onde existiam agroindústrias canavieiras que atuavam como forças motrizes e faliram.

As variáveis independentes explicativas para o comportamento do PIB, que resultaram em significância estatística, foram: o PIB defasado de um período; IFDM educação; IFDM emprego; área colhida; Quociente Locacional (QL), ambas com relação positiva em relação à variável dependente (PIB). As outras variáveis significativas apresentaram relação negativa (empregos na agricultura; fator experiência; mão de obra masculina), implicando em uma elasticidade na qual o aumento em uma dessas variáveis induziu ao decréscimo do PIB. O indicativo de elasticidades negativas de três variáveis e outros comportamentos de relação positiva com o PIB, como da variável QL, denotam relações com um cenário de falência de uma agroindústria canavieira que atuou como força motriz naquele município.

Posteriormente, utilizou-se o método qualitativo via pesquisa de campo, junto a dez representantes dos setores públicos e privados, todos com forte conhecimento de causa no setor sucroenergético ligados, direta e indiretamente, com usinas selecionadas que deixaram de funcionar. A intenção foi de procurar entender tanto as causas do insucesso das usinas, como as consequências advindas do seu fracasso.

Com a realização das mencionadas pesquisas foi possivel constatar a realidade vivenciada pelas unidades que faliram, bem como seus principais motivos, além das repercussões para os municípios. A maior consequência desse malogro, segundo apontaram os representantes dos setores públicos e privados (de forma geral), deuse na redução de empregos, renda e arrecadação. No caso do fracasso das usinas, apenas o quesito "adversidades climáticas" foi considerado pouco importante e sem importância no questionário aplicado.

Quanto aos fatores considerados determinantes para o fechamento das unidades pesquisadas, verificou-se que a falta de gestão foi o principal motivo para a falência das usinas. Cabe destacar que o crescimento prematuro das unidades de forma não planejada, aliado à falta de preparo dos gestores ("insuficiência de conhecimento administrativo/operacional - gestão e planejamento"), influenciaram notadamente nas dificuldades de enfrentamento dos desafios impostos nesse mercado, além de fragilizar a tomada de decisões e atuação estratégica. Estes foram os únicos fatores que deram 100\% em termos de suas respostas, mas, para o setor privado. Pode-se inferir que o preparo para a gestão empresarial se torna um diferencial competitivo para o alcance de resultados positivos, sobretudo quando outras empresas do mesmo setor continuam operando e obtendo resultados positivos.

Por fim, sem a pretensão de esgotar a discussão sobre o assunto falência das usi- 
nas, premente se faz ampliar espaços para novos trabalhos acadêmicos, um dos princípios da pesquisa científica. Até porque, embora interessantes e desafiadoras, as abordagens quantitativa e qualitativa não estão isentas de críticas, principalmente em relação ao tamanho da amostra e checagem da validade das respostas. Neste sentido, a sugestão para novos estudos perpassa pela comparação entre as agroindústrias canavieiras que faliram com as que estão em situação oposta, ou mesmo estudar o malogro das agroindústrias canavieiras em outros estados do Brasil. Acredita-se que isto permitirá conhecer melhor os fatores que favorecem o êxito organizacional, de maneira que seja possivel identificar se outros aspectos estão atrelados com o insucesso ou sucesso das agroindústrias canavieiras.

\section{Referências}

Alves, L. R. A. e Assis, P. F. S. (2001). Fontes de crescimento das principais culturas do Estado do Paraná (1981-1999). Revista Paranaense de Desenvolvimento, (101):1732.

Arellano, M. e Bond, S. (1991). Some tests of specification for panel data: Monte Carlo evidence and an application to employment equations. Review of Economic Studies, 58(2):277-297.

Bastian, A., Gaffuri, J. K. F., Piacenti, C. A., e Margarido, M. A. (2020). Produtividade na agropecuária paranaense. In: Shikida, P. F. A., Galante, V. A., e Cattelan, R., editores, Agronegócio paranaense: potencialidades e desafios II. IDESF, Foz do Iguaçu.

Bechlin, A. R., Mantovani, G. G., Piffer, M., e Shikida, P. F. A. (2020). Alterações na estrutura produtiva e no mercado de trabalho formal decorrentes da falência de uma agroindústria canavieira em Engenheiro Beltrão e Perobal (PR). Informe GEPEC, 24(2):249-274.

Bernardelli, L. V., Paschoalino, P. A. T., Gobi, J. R., e Michellon, E. (2018). A formalização do trabalho na agricultura: uma análise das microrregiões do Estado do Paraná. Revista Paranaense de Desenvolvimento, 39(135):47-67.

Bernardo, L. V. M., Amaral, J. A. d. S., Rodrigues, K. C. T. T., e Shikida, P. F. A. (2018). Reasons and consequences of the bankruptcy of a sugarcane agroindustry: a case study in Engenheiro Beltrão (Paraná/Brazil). Custos e Agronegócio on line, 14(4):282-304.

Blundell, R. e Bond, S. (1998). Initial conditions and moment restrictions in dynamic panel data models. Journal of Econometrics, 87(1):115-143.

Borges, J. C. e Caetano, M. R. (2016). Atividades econômicas, geração de emprego e a relação com o desenvolvimento do município de Capão da Canoa (RS). COLÓQUIORevista do Desenvolvimento Regional, 13(2):85-103. 
Costa, P. F. F. d., Santos, S. L. d., Silva, M. S. d., e Gurgel, I. G. D. (2017). Prevalência de transtorno mental comum entre trabalhadores canavieiros. Revista de Saúde Pública, 51(113):1-10.

Cruz, A. C., Malacoski, F. C. F., e Shikida, P. F. A. (2019). Fatores de insucesso das agroindústrias canavieiras nos estados de Mato Grosso, Mato Grosso do Sul e Minas Gerais. Revista de Economia Mackenzie, 16(1):84-104.

Dalchiavon, E. C. e de Mello, G. R. (2015). Produção do setor rural e o desenvolvimento socioeconômico: um estudo nos municípios paranaenses. Revista da FAE, 18(1):8699.

Ferreira, M. D. P. e Vieira Filho, J. E. R. (2019). Política de preços dos combustíveis. In: Vieira Filho, J. E. R., editor, Diagnóstico e desafios da agricultura brasileira, Página 207-226. IPEA, Rio de Janeiro.

Gama, F. J. C. (2013). Moeda e crescimento: Uma análise para os municípios brasileiros (2000 a 2010). Dissertação (Mestrado em Economia), Universidade Federal de Juiz de Fora, Juiz de Fora.

Gitman, L. J. (2010). Princípios de administração financeira. Pearson Prentice Hall, São Paulo, 12 edition.

Goebel, M. A., Cavalcante, D. L., Clein, C., Moreno, J., e Shikida, P. F. A. (2020). Judicial recovery and bankruptcy of sugarcane agroindustries in the State of Paraná. Revista Brasileira de Gestão e Desenvolvimento Regional, 16(2).

Graef, C. E., Sigolo, É. A., Subeldia Junior, O. L. L., Wiechork, S., e Shikida, P. F. A. (2016). Concentração na agroindústria canavieira paranaense (safras 2000/2001, 2014/2015). Revista de Economia, 42(1).

Gujarati, D. N. e Porter, D. C. (2011). Econometria básica-5. AMGH, Porto Alegre, 5 edition.

IBGE-Instituto Brasileiro de Geografia e Estatística (2021). Cidades. Disponível em: https://cidades.ibge.gov.br/. Acesso em: 07 jan. 2021.

Infocana (2018). Mapa interativo: situação produtiva das usinas sucroenergéticas. Disponível em: https://www.infocana.com.br/dados-etanol-acucarsucroenergetico/. Acesso em: 14 jan. 2021.

MAIOR usina de cana-de-açúcar do Paraná... (2019). Maior usina de canade-açúcar do Paraná entra em recuperação judicial. Disponível em: https://contraponto.jor.br/usina-de-cana-de-acucar-recuperacao-judicial/. Acesso em: 28 jan. 2021.

Mattei, L. (2015). Emprego agrícola: cenários e tendências. Estudos avançados, 29(85):35-52. 
Mattei, L. (2018). Os efeitos da crise econômica de 2015-2017 sobre o mercado de trabalho brasileiro. In: Prates, D. e Terra, F., editores, Dossiê V da Associação Keynesiana Brasileira, Página 113-123.

Minayo, M. C. d. S., editor (2002). Pesquisa social: teoria, método e criatividade. Vozes, Petrópolis, 21 edition.

Ministério da Economia (202 1). Cide-combustiveis (contribuição de intervenção no domínio econômico incidente sobre as operações realizadas com combustiveis). Disponivel em: https://receita.economia.gov.br/acesso-rapido/tributos/cide. Acesso em: 27 mai. 2021.

Moraes, M. A. F. D. d. (2007). O mercado de trabalho da agroindústria canavieira: desafios e oportunidades. Economia Aplicada, 11(4):605-619.

MTE-Ministério do Trabalho e do Emprego (2021). Relação Anual de Informações Sociais. Disponível em: http://bi.mte.gov.br/bgcaged/rais.php. Acesso em 19 jan. 2021.

Neves, M. F., Pinto, M. J. A., Conejero, M. A., e Trombin, V. G. (2011). Food and fuel: the example of Brazil. Wageningen Academic Publishers, Wageningen.

Novacana (2018). Usinas falidas ou em recuperação judicial. Disponível em: https://www.novacana.com/usinas_brasil/. Acesso em: 16 jan. 2021.

Novacana (2019a). Disparidade nas usinas enfraquece investimentos. Disponível em: https://www.novacana.com/n/eventos/manoel-pereira-queiroz-rabobankdisparidade-usinas-enfraquece-investimentos-280819. Acesso em: 27 jan. 2021.

Novacana (2019b). Em 2019, 23\% das usinas brasileiras de cana-de-açúcar estarão paradas. Disponivel em: https://www.novacana.com/n/industria/usinas/201923-usinas-cana-de-acucarbrasileiras-paradas-050419. Acesso em: 20 jan. 2021.

Paulino, A. D. e Rossi, S. M. M. (2003). Um estudo de caso sobre perfil empreendedor: características e traços de personalidade empreendedora. In: EGEPE - $3^{\circ}$ Encontro de Estudos sobre Empreendedorismo e Gestão de Pequenas Empresas, Página 205220. UEM/UEL/UnB, Brasília.

Pereira, H. J. e Santos, S. A. (1995). Criando seu própio negócio: como desenvolver o potencial empreendedor. Sebrae, Brasília.

Pina, H. (1972). A agro-indústria açucareira e sua legislação. APEC, Rio de Janeiro.

Ramos, C. S. (2017). Cresce o número de falências entre usinas sucroalcooleiras. Disponivel em: http://www.valor.com.br/agro/5131622/cresce-o-numero-defalencias-entre-usinas-sucroalcooleiras. Acesso em: 14 jan. 2021.

Rissardi Júnior, D. J. (2015). Três ensaios sobre a agroindústria canavieira no Brasil pós-desregulamentação. Tese (Doutorado em Desenvolvimento Regional e Agronegócio), Universidade Estadual do Oeste do Paraná (UNIOESTE), Toledo. 
Rodrigues, L. (2015). Politicas públicas e os determinantes da demanda por combustíveis leves no Brasil, 2003-2013. Tese (Doutorado em Economia Aplicada), Escola Superior de Agricultura "Luiz de Queiroz" (ESALQ/USP), Piracicaba.

Rodrigues, L. e Rodrigues, L. (2018). Economic-financial performance of the Brazilian sugarcane energy industry: An empirical evaluation using financial ratio, cluster and discriminant analysis. Biomass and Bioenergy, 108:289-296.

Shikida, P. F. A. e Cattelan, R. (2020). Evolução e dinâmica no setor sucroenergético brasileiro. In: Vieira Filho, J. E. R. e Gasques, J. G., editores, Uma jornada pelos contrastes no Brasil: cem anos do Censo Agropecuário, Página 361-374. IPEA/IBGE/Neagro, Brasília.

Silva, H. J. T. d. (2019). Dois ensaios empíricos sobre heterogeneidade produtiva e estrutura de capital do setor sucroenergético brasileiro. Tese (Doutorado em Economia Aplicada), Escola Superior de Agricultura "Luiz de Gueiroz" (ESALQ/USP), Piracicaba.

Siqueira, P. H. d. L., Shikida, P. F. A., e Cardoso, B. F. (2017). Impact of mergers and acquisitions on the performance of the sugar and alcohol industry in Brazil. Rivista di Economia Agraria, 72(2):151-171.

SNA-Sociedade Nacional da Agricultura (2019). Um novo futuro para o etanol. Disponivel em: https://www.sna.agr.br/um-novo-futuro-para-o-etanol/. Acesso em: 11 jan. 2021.

Szmrecsányi, T. (1979). O planejamento da agroindústria canavieira do Brasil, 19301975. Hucitec/Unicamp, São Paulo.

Tasca, J. A. (2014). Cide combustivel e sua justa destinação. Revista Intervenção, Estado e Sociedade, 1(1):6-21.

Tomasetto, M. Z. d. C., Margarido, M. A., e Shikida, P. F. A. (2013). Transmissão de preços no mercado de cana-de-açúcar entre os estados de São Paulo e Paraná. Revista Brasileira de Estudos Regionais e Urbanos (RBERU), 17(1):19-37.

Tschá, O. d. C. P., de Castro Tomasetto, M. Z., Shikida, P. F. A., Alves, L. R., e Bueno, R. (2010). Encadeamento produtivo, localização e associação geográfica da agroindústria canavieira no Paraná. Redes, 15(1): 128-155.

UDOP-União dos Produtores de Bioenergia (2020). Toda colheita de cana no Paraná deve ser mecanizada até 2025, diz associação. Disponível em: https://www.udop.com.br/noticia/2020/11/09/toda-colheita-de-cana-noparana-deve-ser-mecanizada-ate-2025-diz-associacao.html. Acesso em: 09 jan. 2021.

UNICA-União da Indústria de Cana-de-Açúcar (2021). Observatório da cana. Disponível em: https://observatoriodacana.com.br/. Acesso em: 26 jan. 2021. 
Vergara, S. C. (2007). Métodos de pesquisa em administração. Atlas, São Paulo, 9 edition.

Wooldridge, J. M. (2010). Econometric analysis of cross section and panel data. MIT press, Cambridge, 2 edition.

Wooldridge, J. M. (2011). Introdução à econometria: uma abordagem moderna. Cengage Learning, São Paulo, 4 edition.

(๔) Este artigo está licenciado com uma CC BY 4.0 license. 